\title{
Herbs that Ensure Good Health and Longevity
}

\author{
$\mathrm{J}$ Jainarinesingh
}

\section{INTRODUCTION}

In an effort to balance and monitor blood pressure, any rise in blood pressure must be carefully monitored, studied, treated and controlled.

Hypertension is a conglomeration of physiological, emotional and mental factors. The physiological condition is often aggravated by atherosclerosis and arteriosclerosis, drug abuse and obesity. Cigarettes, alcohol and caffeine are known contributory factors to hypertension. It is now known that mental and emotional hypertension is common in persons who live stressful lives amidst the hustle and bustle of their daily activities.

Keywords: Allium sativum, arteriosclerosis, atherosclerosis, cayenne, garlic, hypertension, Valeriana officinalis

West Indian Med J 2014; 63 (1): 90

\section{DISEASE MANAGEMENT}

\section{Garlic}

Sainani et al (1), Bordia (2) and Jain and Koner (3) postulated that garlic (Allium sativum) is effective in reducing high blood pressure, controlling nervous anxiety, lowering serum cholesterol and it is still proven to be an effective management technique. Other research also shows that garlic contains extraordinary therapeutic benefits and almost two dozen major medicinal properties. Garlic can be taken in capsule form, taking two to three capsules, three to four times daily or it can be used as an ingredient in food and drink. The herb also contains volatile sulphur compounds eg allicin as an active ingredient in controlling hypertension. Moreover, garlic-containing diets also markedly produce the lowest cholesterol levels. There are no known side effects and it is an active ingredient in some Asian and Mediterranean dishes.

Research conducted in both humans and rabbits prove that the use of dietary garlic results in a decrease in blood pressure (4). It also reportedly helps to expand blood vessels, thereby improving blood flow and reducing the risk of occluded arteries $(5,6)$. The fact that garlic aids in the expansion of blood vessels can be attributed to the presence of methyl allyl trisulfide, and another known chemical called ajoene helps prevent high blood pressure and heart disease by preventing platelet aggregation $(7,8)$. Furthermore, it is also reported that allicin blocks the biosynthesis of cholesterol by reacting with sulfihydryl group systems and by combining with

From: Chase Village, Chaguanas, Trinidad and Tobago.

Correspondence: Dr J Jainarinesingh, LP 61, John Elie Road, Chase Village, Chaguanas, Trinidad and Tobago. E-mail: jjsingh2005@yahoo.com coenzyme A. In another study, it was found that people who used garlic and onion had reduced serum-triglyceride, beta lipoprotein, phospholipid and plasma fibrinogen levels $(5,9)$.

\section{Valerian}

Another herb called valerian root (Valeriana officinalis) and its major constituents such as the voleapropriates, possess marked sedative, anticonvulsive, hypotensive, tranquilizing, neurotropic and anti-aggressive properties (10-14). This is one of the most widely-studied herbs and its use has been investigated in both humans and animals in countries such as Germany and Russia. The hypotensive, tranquilizing, neurotopic and anti-aggressive properties of the herb result from a selective neurotopic action of valerian root on higher brain centres as reflected in electroencephalograph (EEG) readings of brain waves $(10,12)$.

It has also been reported that the herb's principal function is to suppress and regulate the autonomic nervous system. It is important to note that in Germany, valerian root preparations have been used for almost two decades to treat behavioural disorders in children (15). The herb can be taken orally, two to four capsules daily, with no known side effects.

\section{Cayenne}

Yet another potent herb named cayenne (Capsicum annuum) is reportedly capable of reducing hypertension, nervous anxiety and lowering serum cholesterol. Cayenne contains an active ingredient called capsaicin which helps to reduce systemic blood pressure - a type of coronary chemoreflex.

Cayenne is widely known to lower blood cholesterol levels thus assisting in the lowering of blood pressure $(10,11)$. In one study, separate groups of rats were fed diets high in cholesterol with or without ground cayenne or capsaicin for seven weeks (14). The results revealed that both cayenne and capsaicin prevented a rise in liver cholesterol levels and increased faecal excretions of free cholesterol (14). These research outcomes prevent even the absorption of cholesterol. It was also found that cayenne was more effective than capsaicin alone on all counts, thus proving that, as often obtains in pharmaceutical sciences, the use of isolated constituents may ignore the beneficial effects of principles left behind in the dross. Cayenne has no side effects and can be taken in doses of two to three capsules three to four times daily.

Overall, herbs are gifts of Mother Nature that provide us with natural remedies for almost every element. Herbs and other natural preparations are still used by all indigenous groups throughout South America. In fact, many medical doctors are now treating their patients with both natural and allopathic medicines with very encouraging results. 


\section{REFERENCES}

1. Sainani GS, Desai DB, More KN. Letter: Onion, garlic and atherosclerosis. Lancet 1976; 2: 575-6.

2. Bordia A. Effect of garlic on blood lipids in patients with coronary heart disease. Am J Clin Nutr 1981; 34: 2100-3.

3. Jain RC, Koner DB. Onion and garlic in experimental cholesterol atherosclerosis in rabbits: effect on serum proteins and development of atherosclerosis. Artery 1976; 2: 531-9.

4. Bordia A, Verma SK, Vyas AK, Khabya BL, Rathore AS, Bhu N et al. Effect of essential oil of onion and garlic on experimental atherosclerosis in rabbits. Atherosclerosis 1977; 26: 379-86.

5. Jain RC. Onion and garlic in experimental cholesterol induced atherosclerosis. Indian J Med Res 1976; 64: 1509-15.

6. Temple KH. Effect of garlic on experimental cholesterol atherosclerosis in rabbits. Medizin und Erhaerung 1962; 3: 197-9.

7. Srivas KC. Effects of aqueous extracts of onion, garlic and ginger on platelet aggregation and metabolism of arachidonic acid in blood vascular system: in vitro study. Prostaglandins Leukot Med 1984; 13: 227-35.
8. Bordia A. Effect of garlic on human platelet aggregation in vitro. Atherosclerosis 1978; 30: 355-61.

9. Makheia AN, Vanderhoek JY, Bailey JM. Inhibition of platelet aggregation and throboxane synthesis by onion and garlic. Lancet 1979; 1: 781.

10. Gstirner F, Kleinbauer E. [Pharmacological tests on valerian root]. Pharmazie 1958; 13: 415-20. In German

11. Hauschild F. [Problems of the sedative effects of valerian]. Pharmazie 1958; 13: 420-2. In German

12. Kempinskas V. [On the action of valerian]. Farmakol Toksikol 1964; 27: 305-9. In Russian

13. Zburzhinskii VK. [Study of the sedative action of valerian]. Farmakol Toksikol 1964; 27: 301-5. In Russian

14. Boeters U. [Treatment of control disorders of the autonomic nervous system with valepotriate (Valmane)]. Munch Med Wochenschr 1969; 111: 1873-6. In German.

15. Klich R. [Behavioural disorders of childhood and their treatment]. Medizinische Welt 1975; 26: 1251-4. In German 